\title{
$\pi$-Conjugated polymer-layered structures: synthesis and self-assembly
}

\author{
Yuichi Tsuji, Yasuhiro Morisaki ${ }^{1}$ and Yoshiki Chujo \\ $\pi$-Conjugated polymers capped with a boronic acid end-functional group were synthesized by chain-growth Suzuki-Miyaura \\ polycondensation. The obtained polymers were reacted with a $\pi$-stacked-polymer scaffold, developed in our previous work. \\ Despite their bulkiness, the conjugated polymers were efficiently introduced into the polymer scaffold. The spectroscopic and \\ optical characterization of the obtained graft polymers in the solid state revealed that the original $\pi$-conjugated polymers were \\ stacked in a single polymer chain. Although excluded volume effects prevented significant intermolecular interactions between \\ the polyfluorenes, the introduced polythiophenes formed intermolecular $\pi$-stacked structures. Direct observations of the obtained \\ graft polymers showed that the graft polymers self-assembled into the spherical or fiber structures depending on the introduced \\ polymers, whereas no ordered structures were formed by the same polymers before the polymer reaction.
} Polymer Journal (2017) 49, 203-208; doi:10.1038/pj.2016.89; published online 28 September 2016

\section{INTRODUCTION}

Because of the formation of highly ordered structures, the supramolecular self-assembly of $\pi$-conjugated compounds ${ }^{1,2}$ can provide new functionalities and lead to unique optoelectronic properties. $^{3-11}$ Because $\pi$-conjugated compounds tend to aggregate by $\pi-\pi$ stacking, the introduction of non-covalent interactions at appropriate positions increases their association constants and facilitates the formation of higher-ordered structures. ${ }^{12,13}$ For example, supramolecular gels can be formed through intermolecular interactions such as hydrogen bonds, ${ }^{14,15}$ and multiple long alkyl chains facilitate columnar stacking along the $\pi$-stacking direction of supramolecular assemblies ${ }^{16-19}$ (Figure 1a). A variety of assembled structures can be formed through covalent linkages between $\pi$-conjugated units (Figure 1b). Flexible linkers enable intramolecular folding, and the resulting folded molecules can adopt unique morphologies such as fibers ${ }^{20-22}$ and two-dimensional nanosheets. ${ }^{23}$ Conjugated linkers extended the $\pi$-conjugation length and the conjugated polymers can form nanofibers through their strong $\pi-\pi$ interactions. ${ }^{24,25}$

Among the different types of linkers, hairpin-shaped rigid linkers can promote the formation of intramolecular $\pi$-stacked structures. ${ }^{26-30}$ We have recently reported the synthesis of polymers with layered aromatic rings using a xanthene scaffold as a hairpin-shaped linker; these polymers exhibit intramolecular $\pi$-stacked structures with multiple aromatic rings stacked along a single polymer chain. ${ }^{31-36}$ They can be regarded as the assembly of several small $\pi$-conjugated units. However, owing to the small size of the $\pi$-conjugated moieties and to the bulkiness of the xanthene scaffold, their intermolecular interactions were relatively weak. Recently, we reported a versatile polymer reaction method for the construction of aromatic ring-layered structures. ${ }^{37}$ This method enables the production of $\pi$-stacked structures for a wide variety of $\pi$-electron systems. Herein, we used $\pi$-conjugated polymers as the stacked $\pi$-electron systems and an aromatic ring-layered polymer as a scaffold to synthesize $\pi$-conjugated polymer-layered structures, in which the $\pi$-conjugated polymers were grafted on the aromatic ring-layered scaffold. The rigid scaffold holds the $\pi$-conjugated polymers in a $\pi-\pi$ stacking arrangement; the ordered structure of which enhances the intermolecular interactions between the polymers, resulting in the formation of spherical- or fiber-like structures.

\section{RESULTS AND DISCUSSION}

We applied catalyst-transfer Suzuk-Miyaura coupling ${ }^{38-43}$ to synthesize end-functionalized poly(3-hexylthiophene) (P3HT) and poly(fluorene) (PF). As shown in Scheme 1, polymerization of AB-type monomers $\mathbf{2}$ and $\mathbf{3}$ with the palladium initiator $\mathbf{1}$ ([monomer $]_{0} /[\mathbf{1}]_{0}=20$ ) was used to prepare boron-masking 44 polymers P3HT-BDAN and PF-BDAN. End-functionalization of the one terminal of the polymer was confirmed by ${ }^{1} \mathrm{H}$ NMR using the signals arising from the end-functionalized pyrenes and matrix-assisted laser desorption/ionization time-of-flight mass spectrometry. The values for the degree of polymerization of P3HT-BDAN and PF-BDAN were estimated to be 20 and 18, respectively, with almost $100 \%$ regioregularity (Supplementary

Department of Polymer Chemistry, Graduate School of Engineering, Kyoto University, Kyoto, Japan

${ }^{1}$ Current address: Department of Applied Chemistry for Environment, School of Science and Technology, Kwansei Gakuin University, 2-1 Gakuen, Sanda, Hyogo 669-1337, Japan.

Correspondence: Professor Y Morisaki or Professor Y Chujo, Department of Applied Chemistry for Environment, Kwansei Gakuin University, 2-1 Gakuen, Sanda, Hyogo 669-1337 Japan.

E-mail: ymo@kwansei.ac.jp or chujo@chujo.synchem.kyoto-u.ac.jp

Received 10 July 2016; revised 3 August 2016; accepted 3 August 2016; published online 28 September 2016 
a

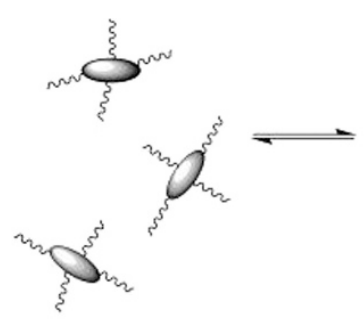

b

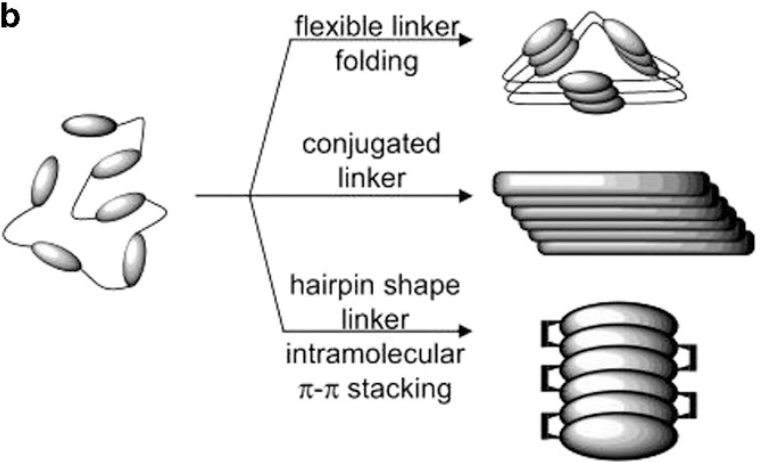

Figure 1 Examples of self-assemblies: (a) conjugated compounds and (b) covalently bonded conjugated compounds.
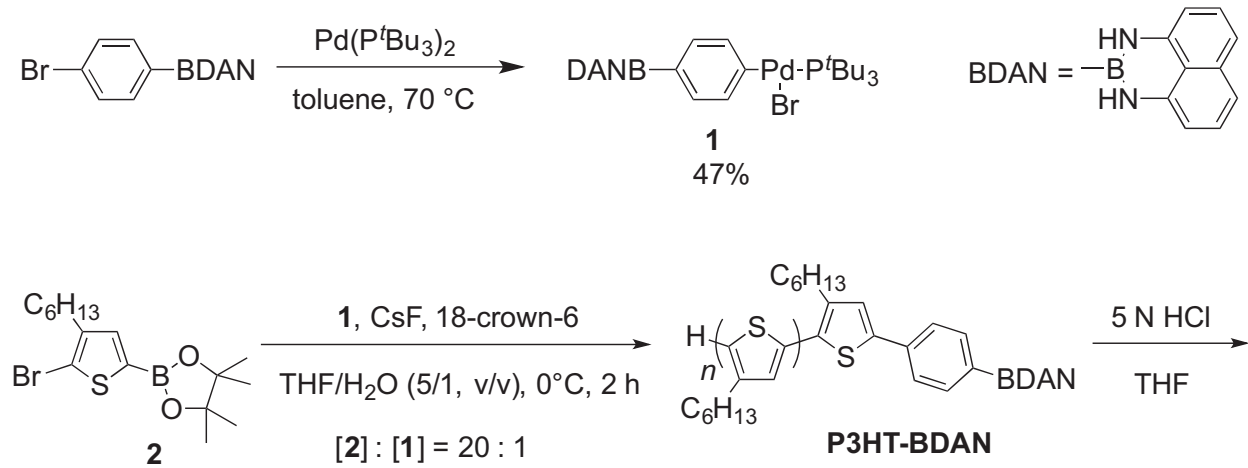

regio: $\mathrm{HT}>99 \%, M_{\mathrm{n}}: 4000$, $\mathrm{PDI}: 1.3$,

DP(GPC): 22, DP( $\left.{ }^{1} \mathrm{H} N M R\right): 20$

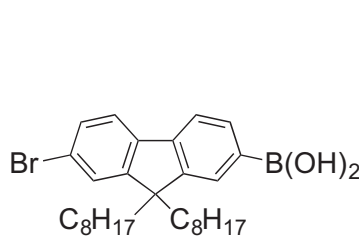

3

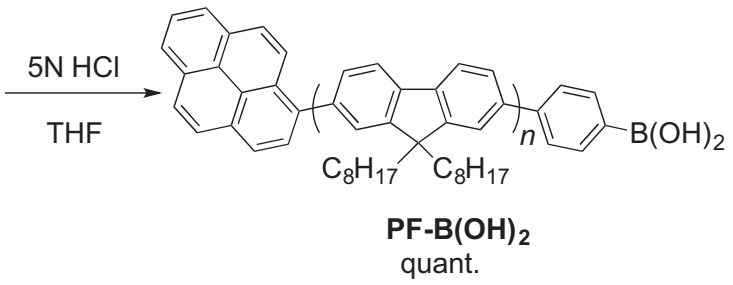

$(\mathrm{HO})_{2} \mathrm{~B}$

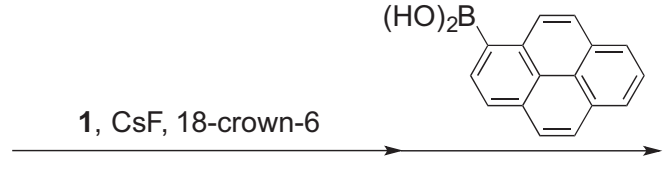

$\mathrm{THF} / \mathrm{H}_{2} \mathrm{O}(10 / 1, \mathrm{v} / \mathrm{v}), 0^{\circ} \mathrm{C}, 2 \mathrm{~h}$

THF

$[3]:[1]=20: 1$

$\mathrm{DP}(\mathrm{GPC}): 24, \mathrm{DP}\left({ }^{1} \mathrm{H}\right.$ NMR): 18

Scheme 1 Synthesis of a Pd initiator and end-functionalized polymers. GPC, gel-permeation chromatography; ${ }^{1} \mathrm{H}$ NMR, proton nuclear magnetic resonance.

Figure S3-S6 and Supplementary Figure S13-S16). After the deprotection of boronic acid, the polymer reaction of the polymer precursor (aromatic ring-layered polymer) P1 with $\mathrm{P} 3 \mathrm{HT}-\mathrm{B}(\mathrm{OH})_{2}$ or $\mathrm{PF}-\mathrm{B}(\mathrm{OH})_{2}$ was carried out under conditions similar to those reported in the literature (Scheme 2). ${ }^{37}$ Grafting of P3HT and PF polymers to the scaffold was confirmed by Fourier Transform-Infrared (FT-IR) spectroscopy and gel-permeation chromatography, as shown in Supplementary Figure S15-S17. Only the peak arising from boronate esters at $1350 \mathrm{~cm}^{-1}$ was observed in both cases, with no peaks corresponding to the unreacted hydroxyl groups, and the molecular weights of the grafted polymers P3HT-P and PF-P were found to be much larger than those of P3HT-BDAN and PF-BDAN. The polymer reaction thus proceeded almost quantitatively, despite the low concentration of the boronic acid moiety in both P3HT-B $(\mathrm{OH})_{2}$ and PF$\mathrm{B}(\mathrm{OH})_{2}$. Structures of all new compounds were confirmed by ${ }^{1} \mathrm{H}$ and ${ }^{13} \mathrm{C}$ NMR spectra (Supplementary Figure S1-S12). 

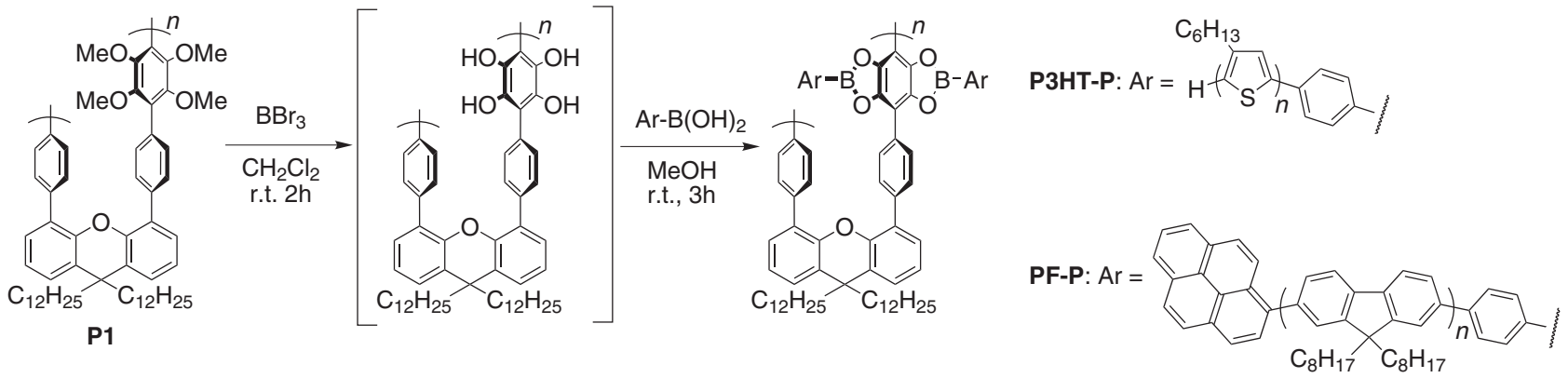

Scheme 2 Polymer reactions of $\mathbf{P} 1$ to synthesize $\pi$-conjugated polymer-stacked polymers $\mathbf{P} 3 \mathrm{HT}-\mathrm{B}(\mathrm{OH})_{2}$ and $\mathrm{PF}-\mathrm{B}(\mathrm{OH})_{2}$.
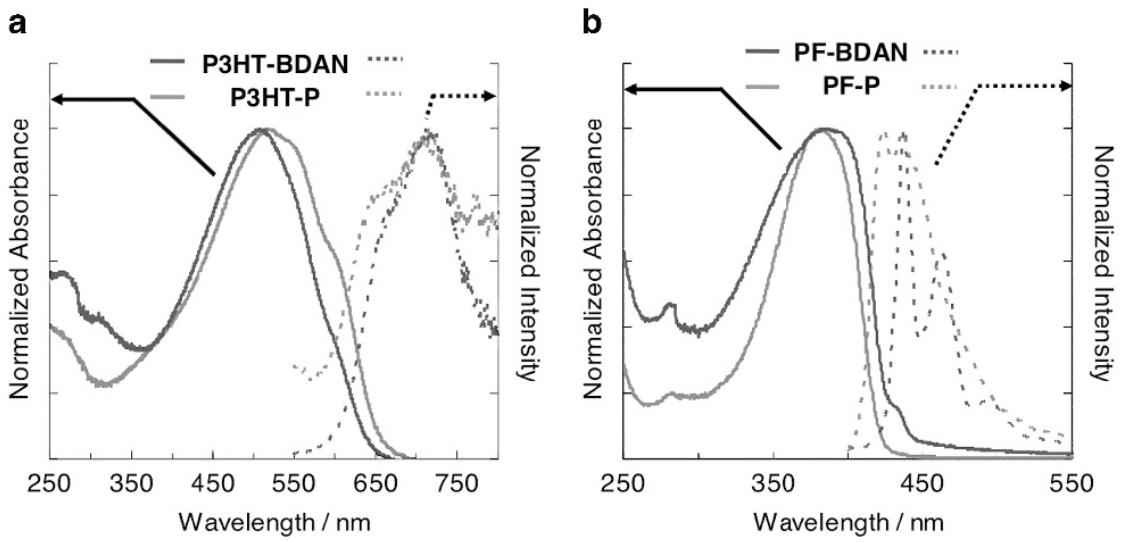

Figure 2 UV-vis absorption and fluorescence spectra of (a) P3HT-P and P3HT-BDAN in $\mathrm{CHCl}_{3}\left(1.0 \times 10^{-5} \mathrm{M}\right.$ ), and (b) PF-P and PF-BDAN in CHCl 3 $\left(1.0 \times 10^{-5} \mathrm{M}\right)$. UV-vis, ultraviolet-visible.

a

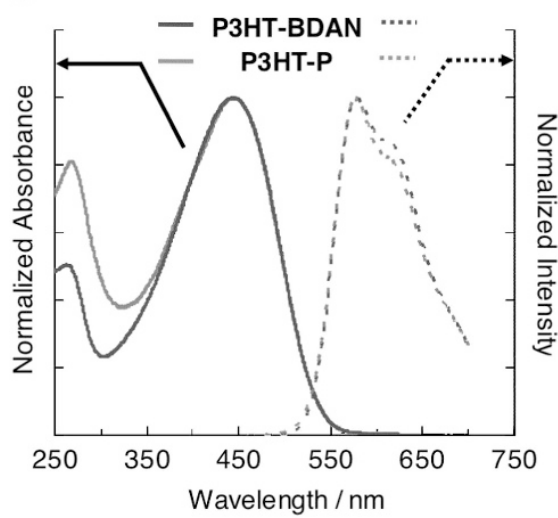

b

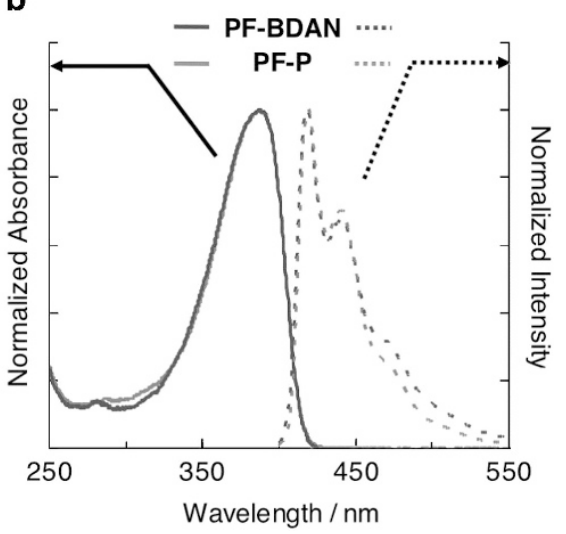

Figure 3 UV-vis absorption (solid line) and fluorescence (dashed line) spectra of (a) P3HT-P film and P3HT-BDAN film, and (b) PF-P film and PF-BDAN film. UV-vis, ultraviolet-visible.

The ultraviolet-visible absorption and fluorescence spectra of the polymers were measured in diluted $\mathrm{CHCl}_{3}$ solutions, with no significant differences emerging in the optical properties measured before and after the polymer reactions (Figure 2). Because the degree of polymerization of the original polymers was sufficiently large and similar to the reported effective conjugation length, ${ }^{45,46}$ the intramolecular interactions within the introduced polymers had little influence on their electronic state. On the other hand, significant differences were observed in the cast films (Figure 3). Polymer P3HT-BDAN was randomly aggregated in the solid state; its absorption peaks were broadened and red-shifted owing to the intermolecular $\pi-\pi$ interactions. The fluorescence emission intensity also decreased and the corresponding spectrum was red-shifted. The main absorption peak of P3HT-P exhibited a further red-shift compared with that of P3HTBDAN, with an absorption shoulder $\sim 600 \mathrm{~nm}$ corresponding to the crystalline P3HT domains in a single polymer chain. ${ }^{47}$ In addition, hardly any emission was detected from P3HT-P. These results suggest that the P3HT units in P3HT-P adopted a well-stacked and more ordered arrangement in the solid state owing to the presence of the xanthene-based polymer scaffold. The X-ray diffraction profile of 
P3HT-P indicated a phase I pattern ${ }^{48}$ in which the hexyl chains of P3HT adopted a lamellar packing, and the $\pi-\pi$ stacking distance among P3HT chains was estimated to be $3.8 \AA$ (Figure 4). However, the crystallinity of the P3HT-P film seemed to decrease. Even though P3HT-BDAN also exhibited a phase I pattern, the X-ray diffraction peak associated with the $\pi-\pi$ stacking of P3HT units was different; in particular, the intramolecular $\pi-\pi$ stacking peak of P3HT-P in a single polymer chain was strong, and its intensity was similar to that of the peak associated with the lamellar alkyl chains. This was owing to

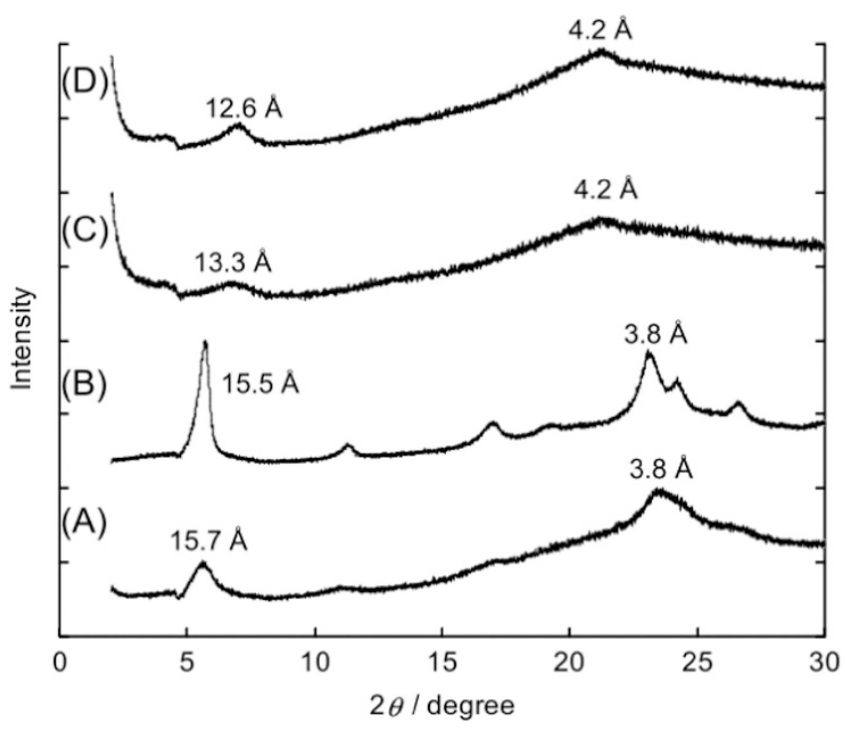

Figure 4 X-ray powder diffraction patterns of (A) P3HT-P, (B) P3HT-BDAN, (C) PF-P and (D) PF-BDAN. Peaks are labeled with $d$ spacing in $\AA$.
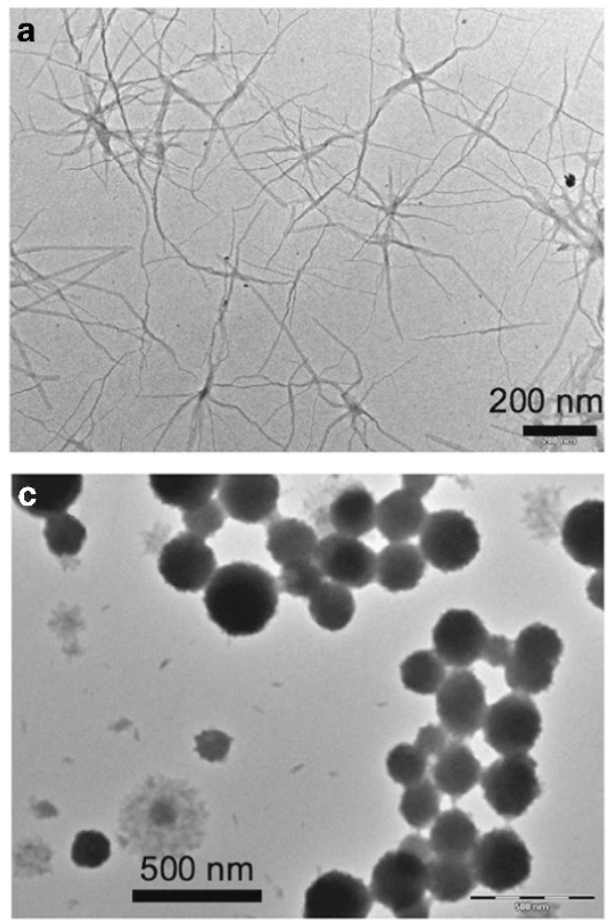

Figure 5 TEM images of (a) P3HT-P, (b) P3HT-BDAN, (c) PF-P and (d) PF-BDAN. All samples were prepared from $\mathrm{CHCl}_{3} / \mathrm{EtOH}(\mathrm{v} / \mathrm{v}=3 / 1$ ) mixed solvent. TEM, transmission electron microscopy.
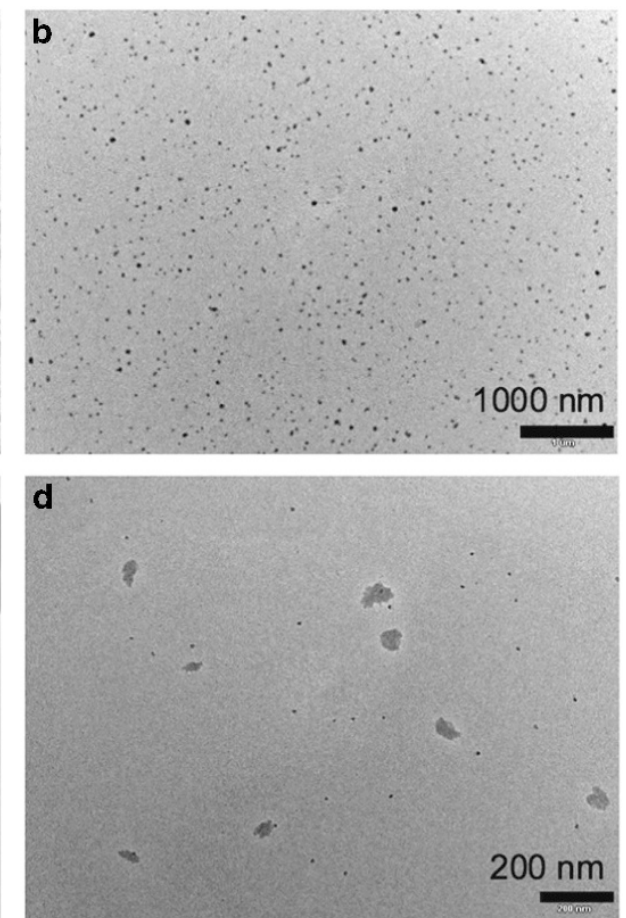

the fixation of the P3HT units by the xanthene-based polymer scaffold, as shown in the previous work. ${ }^{37}$

The absorption spectrum of PF-BDAN was red-shifted and broadened, and the emissions spectrum was also red-shifted in the film. These results suggest the presence of significant interchain interactions in these polymers, supported by the X-ray diffraction patterns indicative of their planar $\beta$-phase, ${ }^{49}$ and highlighting the planarity and intermolecular stacking of the PF backbones (Supplementary Figure S18). The small shoulder absorption band in the ultraviolet spectrum and clear vibrational structure in the photoluminescence (PL) spectrum of PF-BDAN arose from the pyrene moieties. On the other hand, the absorption peak of PF-P in the film was slightly blue-shifted (by $\sim 2 \mathrm{~nm}$ ) compared with the peak detected in solution without any peak-broadening. In addition, the emission peak of PF-P in the film was similar to the peak obtained in $\mathrm{CHCl}_{3}$ solution. The $2 \theta$-value in the X-ray diffraction profile of PF-P is indicative of the $\alpha$-phase, ${ }^{49}$ suggesting that the PF backbones in PF$\mathbf{P}$ are twisted (Supplementary Figure S18), leading to the blue-shifted absorption spectrum. Thus, the PFs of PF-P were layered in a single polymer chain; however, planarization of the PF backbones was prevented by the alkyl chains of neighboring PFs, the large excluded volume of which, in turn, inhibited the intermolecular interactions between their $\pi$-systems.

The different intermolecular interactions displayed by the polymers in solution and in a film were further explored by examining their assembling behavior using transmission electron microscopy. Cast films were obtained from a $\mathrm{CHCl}_{3} / \mathrm{EtOH}$ solution. As shown in Figure 5a, P3HT-P self-assembled into fibrous structures, whereas P3HT-BDAN formed small particles (Figure 5b). Fibers of various widths ranging from $20 \mathrm{~nm}$ to $100 \mathrm{~nm}$ were observed; $20 \mathrm{~nm}$ was approximately twice the value of the P3HT-BDAN chain length ( $n=20, \sim 9 \mathrm{~nm}$ ), corresponding to the width of a single P3HT-P 

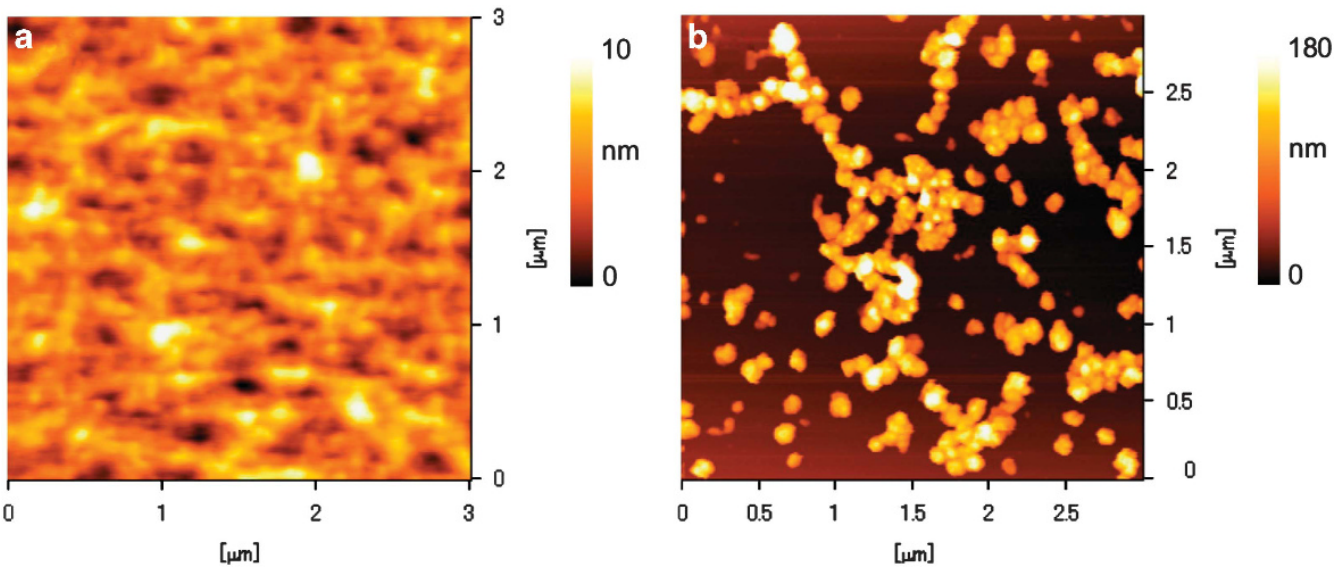

$\mathrm{nm}$

Figure 6 (a) AFM image of P3HT-P and (b) AFM image of PF-P. Samples were prepared from $\mathrm{CHCl}_{3} / \mathrm{EtOH}(\mathrm{v} / \mathrm{V}=3 / 1)$ solution. AFM, atomic force microscopy.

molecule. The height of the fibers was $10 \mathrm{~nm}$ at most, as deduced from the atomic force microscopy image of P3HT-P shown in Figure 6a. Thus, P3HT-P assembled into the fibers through one-directional elongation along the stacking direction owing to the alignment of the P3HT units by the rigid polymer scaffold. On the other hand, P3HT-BDAN was not tightly pinned onto the scaffold, resulting in entanglement and particle formation instead of intermolecular $\pi-\pi$ stacking and elongation.

As shown in Figure 5c, PF-P self-assembled into submicrometer particles, whereas PF-BDAN formed aggregates of nanometer size (Figure 5d), similarly to P3HT-BDAN. A large number of aggregated particles by aggregation were also observed in the atomic force microscopy image of PF-P (Figure 6b), and their spherical shape was confirmed on the basis of their height information $(\sim 170 \mathrm{~nm}$ on average, Supplementary Figure S19). The average particle size of PF-P was estimated to be $184.6 \mathrm{~nm}$ (by transmission electron microscopy), $194.1 \mathrm{~nm}$ (by atomic force microscopy) and $191.0 \pm 21.4 \mathrm{~nm}$ (by dynamic light scattering, Supplementary Figure S20). Some of the particles shown in Figure 5c exhibited high contrast in the core region and low contrast at the edge where small fragments with high aspect ratio were observed. These particles were thought to be formed during the association. The small fragments were supposed to be single PF-P molecules, whose longer side length was estimated to be $\sim 35-40 \mathrm{~nm}$, approximately twice the value of the PF-BDAN chain length $(n=18, \sim 17 \mathrm{~nm})$. PF-P and PF-BDAN tended to form particles for the same reason discussed above for P3HT-BDAN; larger particles were formed in the case of PF-P owing to the larger size of the single PF-P molecule. On the basis of results of the optical measurements, and direct observations by transmission electron microscopy and atomic force microscopy, we can conclude that the grafting of $\pi$-conjugated polymers within a polymer scaffold facilitates the formation of higher-ordered structures with morphologies that depend essentially on the nature of the grafted $\pi$-conjugated polymers.

In summary, we prepared $\pi$-conjugated polymers end-capped with boronic acid (P3HT-B $(\mathrm{OH})_{2}$ and $\left.\mathrm{PF}-\mathrm{B}(\mathrm{OH})_{2}\right)$ by chain-growth Suzuki-Miyaura polymerization. Condensation of the polymers with an aromatic ring-layered polymer scaffold yielded $\pi$-conjugated polymer-grafted polymers P3HT-P and PF-P. Despite their bulkiness, the conjugated polymers were efficiently introduced into the polymer scaffold. The polymer scaffold facilitated the formation of $\pi$-stacked P3HT structures with enhanced crystallinity. On the other hand, PFs were located close to each other in the scaffold; thus, their main chains were twisted, suppressing the intermolecular interactions among the PF units. P3HT-P self-assembled into fibers by one-directional elongation along the $\pi-\pi$ stacking direction, whereas PF-P aggregated to form submicrometer particles. The present results show that the polymer scaffold can assist in the self-assembly process by pinning down the $\mathrm{P} 3 \mathrm{HT}$ or PF units within a single polymer chain acting as a nucleus for the formation of higher-ordered structures. Dependence of the morphology on the molecular weights of the scaffold and grafting polymers, as well as the optoelectronic properties of the self-assemblies will be discussed in the future.

\section{CONFLICT OF INTEREST}

The authors declare no conflict of interest.

\section{ACKNOWLEDGEMENTS}

YT appreciates Research Fellowships (No. 11J00830) from the Japan Society for the Promotion of Science for Young Scientists.

1 Brunsveld, L., Folmer, J. B., Meijer, E. W. \& Sijbesma, R. P. Supramolecular polymers. Chem. Rev. 101, 4071-4097 (2001).

2 Hoeben, F. J. M., Jonkheijm, P., Meijer, E. W. \& Schenning, A. P. H. J. About supramolecular assemblies of $\pi$-conjugated systems. Chem. Rev. 105, 1491-1546 (2005).

3 Yamaguchi, T., Kimura, T., Matsuda, H. \& Aida, T. Macroscopic spinning chirality memorized in spin-coated films of spatially designed dendritic zinc porphyrin J-aggregates. Angew. Chem. Int. Ed. 43, 6350-6355 (2004).

4 Würthner, F., Chen, Z., Hoeben, F. J. M., Osswald, P., You, C. C., Jonkheijm, P., Herrikhuyzen, J., Schenning, A. P. H. J., van der Schoot, P. P. A. M., Meijer, E. W., Beckers, E. H. A., Meskers, S. C. J. \& Janssen, R. A. J. Supramolecular $\mathrm{p}$-n-heterojunctions by co-self-organization of oligo(p-phenylene vinylene) and perylene bisimide dyes. J. Am. Chem. Soc. 126, 10611-10618 (2004).

5 Das, A., Molla, M. R., Maity, B., Koley, D. \& Ghosh, S. Hydrogen-bonding induced alternate stacking of donor (D) and acceptor (A) chromophores and their supramolecular switching to segregated states. Chemistry 18, 9849-9859 (2012).

6 Lemaur, V., da Silva Filho, D. A., Coropceanu, V., Lehmann, M., Geerts, Y., Piris, J. Debije, M. G., van de Craats, A. M., Senthilkumar, K., Siebbeles, L. D. A., Warman, J. M., Brédas, J. L. \& Cornil, J. Charge transport properties in discotic liquid crystals: a quantum-chemical insight into structure-property relationships. J. Am. Chem. Soc. 126, 3271-3279 (2004).

7 Debije, M. G., Piris, J., de Haas, M. P., Warman, J. M., Tomović, Ž., Simpson, C. D. \& Müllen, K. The optical and charge transport properties of discotic materials with large aromatic hydrocarbon cores. J. Am. Chem. Soc. 126, 4641-4645 (2004).

8 Yasuda, T., Kishimoto, K. \& Kato, T. Columnar liquid crystalline $\pi$-conjugated oligothiophenes. Chem. Commun. 3399-3401 (2006).

9 Feng, X., Marcon, V., Pisula, W., Hansen, M. R., Kirkpatrick, J., Grozema, F., Andrienko, D., Kremer, K. \& Müllen, K. Towards high charge-carrier mobilities by rational design of the shape and periphery of discotics. Nat. Mater. 8, 421-426 (2009). 
10 Verilhac, J.-M., LeBlevennec, G., Djurado, D., Rieutord, F., Chouiki, M., Travers, J.-P. \& Pron, A. Effect of macromolecular parameters and processing conditions on supramolecular organisation, morphology and electrical transport properties in thin layers of regioregular poly(3-hexylthiophene). Synth. Met. 156, 815-823 (2006).

11 Noriega, R., Rivnay, J., Vandewal, K., Koch, F. P. V., Stingelin, N., Smith, P., Toney, M. F. \& Salleo, A. A general relationship between disorder, aggregation and charge transport in conjugated polymers. Nat. Mater. 12, 1038-1044 (2013).

12 Chen, Z., Lohr, A., Saha-Möller, C. R. \& Würthner, F. Self-assembled $\pi$-stacks of functional dyes in solution: structural and thermodynamic features. Chem. Soc. Rev. 38, 564-584 (2009).

13 De Greef, T. F. A., Smulders, M. M. J., Wolffs, M., Schenning, A. P. H. J., Sijbesma, R. P. \& Meijer, E. W. Supramolecular polymerization. Chem. Rev. 109, 5687-5754 (2009).

14 Schooenbeek, F. S., van Esch, J. H., Wegewijs, B., Rep, D. B. A., de Haas, M. P., Klapwijk, T. M., Kellogg, R. M. \& Feringam, B. L. Efficient intermolecular charge transport in self-assembled fibers of mono- and bithiophene bisurea compounds. Angew. Chem. Int. Ed. 38, 1393-1397 (1999).

15 Ajayaghosh, A. \& George, S. J. First phenylenevinylene based organogels: selfassembled nanostructures via cooperative hydrogen bonding and $\pi$-stacking. J. Am. Chem. Soc. 123, 5148-5149 (2001).

16 Ajayaghosh, A. \& Praveen, V. K. $\pi$-Organogels of self-assembled p-phenylenevinylenes: soft materials with distinct size, shape, and functions. Acc. Chem. Res. 40, 644-656 (2007)

17 Lahieri, S., Thompson, J. L. \& Moore, J. S. Solvophobically driven $\pi$-stacking of phenylene ethynylene macrocycles and oligomers. J. Am. Chem. Soc. 122, $11315-11319$ (2000)

18 van de Craats, A. M., Stutzmann, N., Nielsen, M. N., Watson, M., Müllen, K. Chanzy, H. D., Sirringhaus, H. \& Friend, R. H. Meso-epitaxial solution-growth of selforganizing discotic liquid-crystalline semiconductors. Adv. Mater. 15, 495-499 (2003).

19 Kastler, M., Pisula, W., Wasserfallen, D., Pakula, T. \& Müllen, K. Influence of alkyl substituents on the solution- and surface-organization of hexaperi-hexabenzocoronenes. J. Am. Chem. Soc. 127, 4286-4296 (2005).

20 Cuccia, L. A., Lehn, J. M., Homo, J. C. \& Schmutz, M. Encoded helical self-organization and self-assembly into helical fibers of an oligoheterocyclic pyridine - pyridazine molecular strand. Angew. Chem. Int. Ed. 39, 233-237 (2000).

21 Azeroual, S., Surprenant, J., Lazzara, T. D., Kocun, M., Tao, Y., Cuccia, L. A. \& Lehn, J. M. Mirror symmetry breaking and chiral amplification in foldamer-based supramolecular helical aggregates. Chem. Commun. 48, 2292-2294 (2012).

22 Banno, M., Yamaguchi, T., Nagai, K., Kaiser, C., Hecht, S. \& Yashima, E. Optically active, amphiphilic poly(meta-phenylene ethynylene)s: synthesis, hydrogen-bonding enforced helix stability, and direct AFM observation of their helical structures. J. Am Chem. Soc. 134, 8718-8728 (2012).

23 Zheng, Y., Zhou, H., Liu, D., Floudas, G., Wagner, M., Koynov, K., Mezger, M., Butt, H. J. \& Ikeda, T. Supramolecular thiophene nanosheets. Angew. Chem. Int. Ed. 52, 4845-4848 (2013)

24 Zen, A., Saphiannikova, M., Neher, D., Grenzer, J., Grigorian, S., Pietsch, U., Asawapirom, U., Janietz, S., Scherf, U., Lieberwirth, I. \& Wegner, G. Effect of molecular weight on the structure and crystallinity of poly(3-hexylthiophene). Macromolecules 39, 2162-2172 (2006).

25 Newbloom, G., Weigandt, K. M. \& Pozzo, D. C. Structure and property development of poly(3-hexylthiophene) organogels probed with combined rheology, conductivity and small angle neutron scattering. Soft Matter 8, 8854-8864 (2012).

26 Knoblock, K. M., Silvestri, C. J. \& Collard, D. M. Stacked conjugated oligomers as molecular models to examine interchain interactions in conjugated materials. J. Am. Chem. Soc. 128, 13680-13681 (2006).

27 Jagtap, S. P., Mukhopadhyay, S., Coropceanu, V., Brizius, G. L., Brédas, J. L. \& Collard, D. M. Closely stacked oligo(phenylene ethynylene)s: effect of $\pi$-stacking on the electronic properties of conjugated chromophores. J. Am. Chem. Soc. 134, 7176-7185 (2012)

28 Prabhakaran, P., Puranik, V. G., Chandran, J. N., Rajamohanan, P. R., Hofmann, H. \& Sanjayan, G. J. Novel foldamer structural architecture from cofacial aromatic building blocks. Chem. Commun. 3446-3448 (2009).
29 Yoo, H., Yang, J., Yousef, A., Wasielewski, M. R. \& Kim, D. Excimer formation dynamics of intramolecular $\pi$-stacked perylenediimides probed by single-molecule fluorescence spectroscopy. J. Am. Chem. Soc. 132, 3939-3944 (2010).

30 Yoo, H., Bahng, H. W., Wasielewski, M. R. \& Kim, D. Polymer matrix dependence of conformational dynamics within a $\pi$-stacked perylenediimide dimer and trimer revealed by single molecule fluorescence spectroscopy. Phys. Chem. Chem. Phys. 14, 2001-2007 (2012)

31 Morisaki, Y., Murakami, T., Sawamura, T. \& Chujo, Y. [2.2]Paracyclophane-layered polymers end-capped with fluorescence quenchers. Macromolecules $\mathbf{4 2}$, 3656-3660 (2009).

32 Morisaki, Y., Sawamura, T., Murakami, T. \& Chujo, Y. Synthesis of anthracene-stacked oligomers and polymer. Org. Lett. 12, 3188-3191 (2010).

33 Morisaki, Y., Fernandes, J. A. \& Chujo, Y. Naphthalene-based oligothiophene-stacked polymers. Polym. J. 42, 928-934 (2010).

34 Fernandes, J. A., Morisaki, Y. \& Chujo, Y. $\pi$-Electron-system-layered polymers comprising thiophene/furan oligomers. J. Polym. Sci. A Polym. Chem. 49, 3664-3670 (2011).

35 Morisaki, Y., Nakano, T. \& Chujo, Y. Synthesis and photoluminescence behaviors of anthracene-layered polymers. J. Polym. Sci. A Polym. Chem. 52, 2815-2821 (2014).

36 Nakano, T., Morisaki, Y. \& Chujo, Y. Synthesis of hexabenzocoronene-layered compounds. Tetrahedron Lett. 56, 2086-2090 (2015).

37 Tsuji, Y., Morisaki, Y. \& Chujo, Y. Construction of aromatic-ring-layered structures using the terphenylene-layered polymer as the scaffold. Polym. Chem. 4, 5361-5367 (2013)

38 Yokozawa, T. \& Yokoyama, A. Chain-growth condensation polymerization for the synthesis of well-defined condensation polymers and $\pi$-conjugated polymers. Chem. Rev. 109, 5595-5619 (2009).

39 Yokoyama, A., Miyakoshi, R. \& Yokozawa, T. Chain-growth polymerization for poly(3-hexylthiophene) with a defined molecular weight and a low polydispersity. Macromolecules 37, 1169-1171 (2004)

40 Miyakoshi, R., Yokoyama, A. \& Yokozawa, T. Catalyst-transfer polycondensation. mechanism of $\mathrm{Ni}$-catalyzed chain-growth polymerization leading to well-defined poly (3-hexylthiophene). J. Am. Chem. Soc. 127, 17542-17547 (2005).

41 Miyakoshi, R., Shimono, K., Yokoyama, A. \& Yokozawa, T. Catalyst-transfer polycondensation for the synthesis of poly(p-phenylene) with controlled molecular weight and low polydispersity. J. Am. Chem. Soc. 128, 16012-16013 (2006).

42 Yokoyama, A., Suzuki, H., Kubota, Y., Ohuchi, K., Higashimura, H. \& Yokozawa, T. Chain-growth polymerization for the synthesis of polyfluorene via suzuki-miyaura coupling reaction from an externally added initiator unit. J. Am. Chem. Soc. 129, 7236-7237 (2007)

43 Yokozawa, T., Suzuki, R., Nojima, M., Ohta, Y. \& Yokoyama, A. Precision synthesis of poly(3-hexylthiophene) from catalyst-transfer suzuki - miyaura coupling polymerization. Macromol. Rapid Commun. 32, 801-806 (2011).

44 Noguchi, H., Hojo, K. \& Suginome, M. Boron-masking strategy for the selective synthesis of oligoarenes via iterative Suzuki-Miyaura coupling. J. Am. Chem. Soc. 129, 758-759 (2007)

45 Meier, H., Stalmach, U. \& Kolshorn, H. Effective conjugation length and UV/vis spectra of oligomers. Acta Polym. 48, 379-384 (1997).

46 Wang, Q., Qu, Y., Tian, H., Geng, Y. \& Wang, F. Iterative binomial synthesis of monodisperse polyfluorenes up to 64-mers and their chain-length-dependent properties. Macromolecules 44, 1256-1260 (2011).

47 Brown, P. J., Thomas, D. S., Kohler, A., Wilson, J. S., Kim, J. S., Ramsdale, C. M., Sirringhaus, H. \& Friend, R. H. Effect of interchain interactions on the absorption and emission of poly(3-hexylthiophene). Phys. Rev. B 67, 064203 (2003).

48 Dudenko, D., Kiersnowski, A., Shu, J., Pisula, W., Sebastiani, D., Spiess, H. W. \& Hansen, M. R. A strategy for revealing the packing in semicrystalline $\pi$-conjugated polymers: crystal structure of bulk poly-3-hexyl-thiophene (P3HT). Angew. Chem. Int. Ed. 51, 11068-11072 (2012).

49 Chen, S. H., Su, A. G., Su, C. H. \& Chen, S. A. Crystalline forms and emission behavior of poly(9,9-di-n-octyl-2,7-fluorene). Macromolecules 38, 379-385 (2005).

Supplementary Information accompanies the paper on Polymer Journal website (http://www.nature.com/pj) 